\title{
The Paris Agreement demands climate action
}

Written by: Simon Upton, Director, OECD Environment Directorate

Last update: 14 June 2016

The Paris Agreement is a landmark in collective efforts on climate change and is the result of many years' hard work. It must now be implemented.

\section{Simon Upton, Director, OECD Environment Directorate}

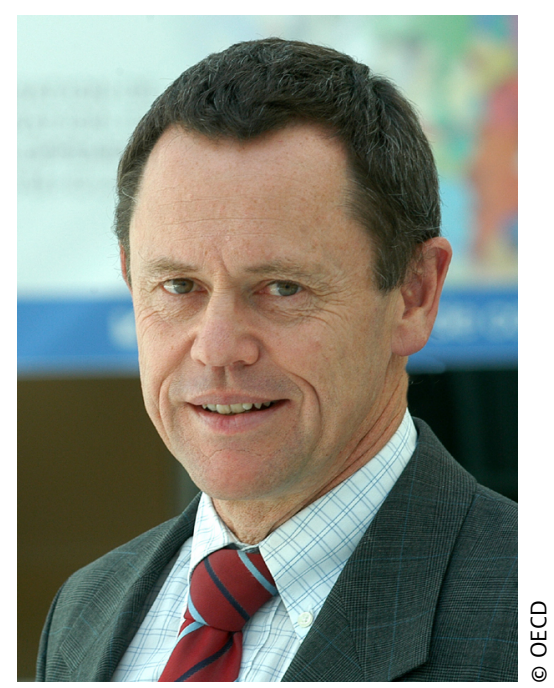

In a remarkable show of solidarity, 177 countries have now signed the Paris Agreement and 16 of them have already deposited their instruments of ratification, acceptance or approval. However, the jury remains out on whether countries will scale up their action sufficiently quickly to achieve the Paris Agreement's long-term aims to limit the extent of climate change to "well below $2^{\circ} \mathrm{C}$ ". The Paris Agreement lays out the foundation for meaningful long-term action, providing transparency and review mechanisms that should allow countries to assess and adjust the scale of their efforts. Over the next few years, parties to the Paris Agreement will be working to finalise these important operational details and rules. Importantly, they also have the opportunity to scale up their emissions reductions efforts before 2020, which is vital if we are to meet the Paris Agreement's stated goals. 
In the run-up to the Paris COP, it was certainly not a foregone conclusion that such an outcome could be achieved. In the end, COP21 saw global climate governance evolve into a hybrid system made up of an overarching transparency, accounting and stock-taking process, complemented by a bottom-up pledge and review process based on the (Intended) Nationally Determined Contributions (INDCs). Successive INDCs are supposed to represent a progression beyond the preceding one and reflect each party's highest possible ambition. All this can be made to work. But every country must act now to deliver on their commitments. The world will not wait, since 2016 is already on track to become yet another "hottest year on record" for the planet .

One feature of the COP mechanisms is their universality. While the type and scale of actions required to implement the Paris Agreement differ across developed and developing countries, all economies will have to mitigate and adapt to the climate challenge, with co-operation at the heart of the agreement so that no country is left behind. The OECD is working with governments around the world to support their efforts to prepare for a changing climate. The way governments manage their potential financial liabilities from climate change needs to be improved. These liabilities include compensation payments, loss of tax revenues and repairing damage to public assets. These "hidden" risks from accumulating damage need to be prevented through better policy choices. In particular, that will mean ensuring that climate resilience is integral to the design, construction and operation of infrastructure networks.

The Paris Agreement recognises that developing countries require tailored support. Much of the detail is still to be worked out, but its "enhanced transparency framework" is intended to help track progress on financial, technology and capacity building support for developing countries, as well as on mitigation and adaptation action. Developed countries extended their current commitment to mobilise US $\$ 100$ billion a year in climate finance by 2020 through to 2025 , with a new collective quantified goal to be set before 2025. The OECD continues to actively support international efforts in improving transparency on climate finance, drawing on the Development Assistance Committee's statistical database for development finance (see www.oecd.org/dac), and the OECD-led Research Collaborative on Tracking Private Climate Finance.

While many developing economies will inevitably increase their emissions for some years to come, development in the 21st century is unlikely to be as fossilintensive as the previous one if the right policies are put in place. Given rapid reductions in the cost of low-carbon alternatives, there is no reason why coalfired power should continue to be the default power option for expanding energy access, for example. The low-carbon transition will have major implications for companies, financial institutions and investments, as new markets emerge, in 
energy technology, construction, transport and so on. The OECD plans to establish a Centre on Green Finance and Investment to help catalyse and support the transition to a green, low-emissions and climate-resilient economy.

Moving away from our historic reliance on fossil fuels implies profound changes to the shape of our economies. These will be challenging for even the most advanced countries. The quality of policies in navigating this transition will be crucial. The core of the policy prescription is clear: a price on emissions of greenhouse gases; the removal of fossil fuel and other pervasive (though sometimes not very transparent) subsidies which run to hundreds of billions of dollars per year and contradict climate targets; regulations to stop excesses where there is urgency and economic instruments are less effective; and support to lowcarbon technologies to get them to the point where they are competitive and attractive to long-term investors.

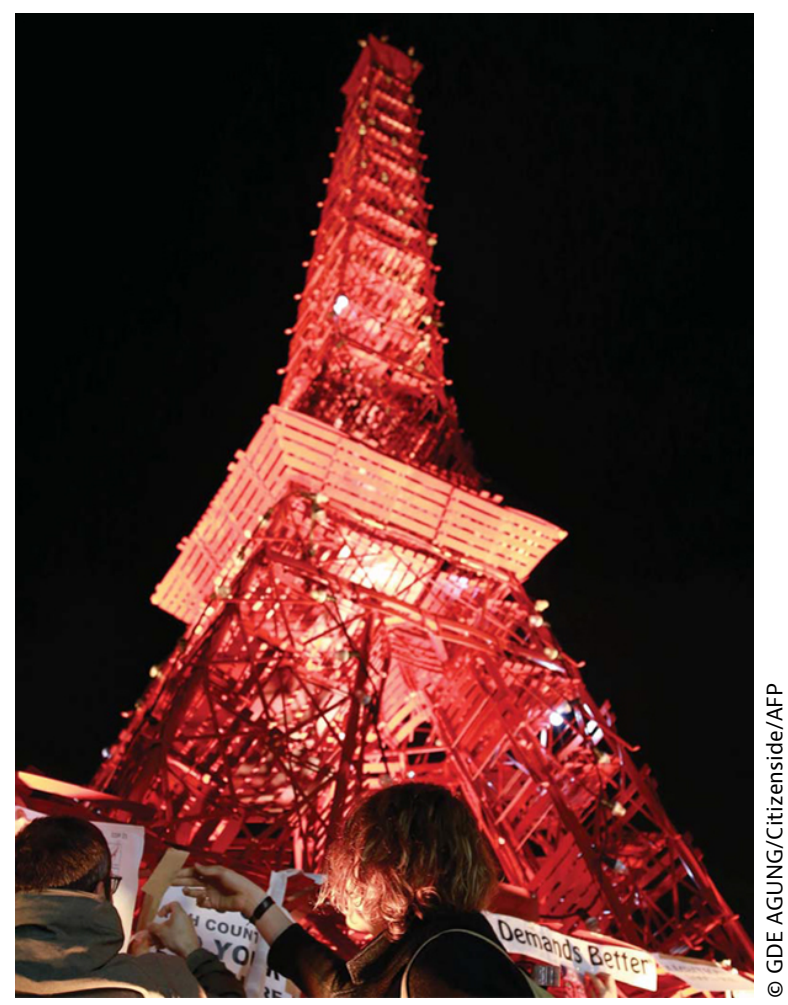

Citizens demand action at the UN climate change conference in Paris in NovemberDecember 2015

A better alignment of policies is needed generally for core climate policies to be effective. Addressing the policy alignment issue is something that all governments can start right away as they begin developing the long-term low greenhouse gas emissions development strategies called for in the Paris Agreement.

Climate action must be structural and inclusive, or it simply won't work. This is all the more important in an era of highly volatile fossil fuel prices. Price instability 
does not encourage efficiency or innovation and it's not good for economic growth. A long-run problem requires policies that send long-run signals. These policies cannot be constantly fine-tuned to the volatility of the moment. As we embark on the implementation phase of the Paris Agreement, the time is ripe for each country to sort out the policy tangle that has grown up over decades and undertake its own diagnosis of policy misalignments. It is then a matter of prioritising actions to ensure that mitigation efforts deliver real outcomes. While there are obvious common elements to any policy roadmap, there is no off-theshelf prescription. Finally, to make the Paris Agreement work, governments need to work systematically through their existing policy settings and make sure they can accommodate new business models and new technologies. The future won't look like the past.

For OECD books, working papers and other references on COP21, visit www.oecd.org/environment/cc/

For articles and references see www.oecdobserver.org/climatechange

\section{References}

OECD Companion to the Inventory of Support Measures for Fossil Fuels 2015 http://dx.doi.org/10.1787/9789264239616-en

Overcoming Barriers to International Investment in Clean Energy http:// dx.doi.org/10.1787/9789264227064-en

Mapping Channels to Mobilise Institutional Investment in Sustainable Energy http://dx.doi.org/10.1787/9789264224582-en

Aligning Policies for a Low-carbon Economy http://dx.doi.org/ 10.1787/9789264233294-en

Climate Change Mitigation http://dx.doi.org/10.1787/9789264238787-en 